degree of activity). ADA-2 isoenzymes were more in chronic form of Gout than in RA. We revealed the simultaneous increase of XO, XDG activities in Gout (XO/XDG activities ratio ? 0.60.8 ), but increased $\mathrm{XO}$ activity in RA was accompanied by normal or lowered XDG activity (XO/XDG activities ratio ? more 1.0).

Conclusion XO, XDG activities changes is more essential in differential diagnostics of RA and Gout among studied enzymatic indices.

\section{AB0153 GOUT IN YUZHNO-SAKHALINSK RESIDENTS}

${ }^{1}$ LM Lazareva, ${ }^{2}$ S Erdesz. ${ }^{1}$ Rheumatology, Municipal Diagnostic Center, Yuzhno-Sakhalinsk; ${ }^{2}$ Epidemiology, Institute of Rheumatology, Moscow, Russia

\subsection{6/annrheumdis-2001.475}

Background Prevalence of gout in the population of Russian cities 20 years ago according to the data of multicentral study was $0.02-0.06 \%$. Since that time there were no studies on epidemiology of this disease.

Objectives To assess the prevalence and clinical manifestations of gout among Sakhalin population (residents of Yuzhno-Sakhalin city).

Methods Clinical manifestations in 120 gout pts $(\mathrm{M}: \mathrm{F}=117: 3$ ) examined in Municipal Diagnostical Centre of the city of Yuzhno-Sakhalinsk from 1990 to 1999 were studied. Population of the city includes $7 \%$ of Koreans and the rest are Slavs.

Results In the result of analysis it was found that gout prevalence among Korean population (300 per 100000 of population) was 6.3 times higher than among Slavs (47 per 100000). In Korean population the disease was found only in males and in Slavs the relation $\mathrm{M}: \mathrm{F}=26: 1$. Among Slavs the median period of gout attack was 7-10 days per year whereas in Koreans 3-5 days by 4-5 times a year. Tofies in Koreans were found in 2\% of cases, and in the rest - in 17\%. Family aggregation of the disease was noticed in $25 \%$ of Korean pts and $7 \%$ in pts of other ethnicity. Conclusion In similar environmental circumstances the prevalence and clinical manifestations of gout are closely related to nationality, that is the certain genotype.

\section{AB0154 PREVALENCE AND CHARACTERISATION OF URIC GOUT DISEASE IN A RHEUMATOLOGY OUTPATIENT'S CLINIC}

MP Mateus, CM Cruz, AC Alves de Matos, JC Branco. Rheumatology Unit, Hospital Egas Moniz, Lisbon, Portugal

\subsection{6/annrheumdis-2001.476}

\section{Background}

Objectives As all other crystal-related arthropathies, uric gout (UG) is a disease that is relatively disabling in its acute phase. There is a lack of published works on the characterisation and prevalence in the portuguese population. The authors' have initiated a study on the sociodemographic and clinical characterisation of the patients with UG of their outpatients rheumatology clinic.

Methods It is a retrospective study, whose data collection took place between May and October 2000, and was later restarted in December 2000. The sample included all patients which presented a UG diagnosis. A 48 variable questionnaire and the patient's clinic register were used for the gathering of data. The questionnaire comprised the patient's identification, professional occupation, clinical profile, changes in the laboratorial and radiological exams, associated diseases, habits, family history. The data analysis was performed using the SPSS 9.0 for Windows software.

Results Of an outpatient's clinic universe of 3000 patients, a total of $39(1.9 \%)$ patients with UG diagnosis was selected. Only 32 of these, were included in the study, representing the sample. It is characterised by an average age of 59.4 and $87.5 \%$ males. The average age at which the first UG crisis happens is 45 . The average duration of crisis without therapeutics is 13.7 days, and with therapeutic is 5.4 days. The average asymptomatic period is variable, with a minimum of 15 days and a maximum of 100 days. In $51.6 \%$ of the patients the first affected joint is the 1 st MTP, followed by the instep, knee and ankle. Globally, the most affected joints are, in decreasing order, 1st MTP and foot, knee, ankle, hand and fingers, elbow, wrist and shoulder. About 33\% of the sample patients show gouty tophi. The precipitating factors can only be identified by $78 \%$ of the patients, and they are, in decreasing order, alcohol + meals, meals, other disease or trauma, alcohol, and cold. The average of the serum uric acid measured at the first appointment is $9.7 \mathrm{mg} / \mathrm{dl}$. The urine uric acid was measured in $50 \%$ of the patients, presenting an average value of $670 \mathrm{mg} / 24 \mathrm{~h}$. The average serum creatinine is $1.7 \mathrm{mg} /$ $\mathrm{dl}$, in which 5 patients had renal impairment. Only 28.1\% of the sample was researched for crystals in sinovial fluid, being positive in $11.1 \%$ of these. X-rays were performed on $53.1 \%$ of the patients, and among these $88.2 \%$ present radiological abnormalities. In what concerns associated diseases, $60 \%$ were obese, having also been considered the following diseases: diabetes, hypertension and hyperlipidemia. Additionally, 35.5\% of the patients have moderate to heavy alcoholic habits, $42.6 \%$ have family history of UG.

Conclusion The results obtained in this study are in good agreement with the published literature concerning the european and north-american population. The sample considered is small due to the fact that this study was paused, and restarted latter, now tuned into the research of monosodium urate monohydrate crystals to confirm the clinical diagnosis.

\section{AB0155 CHRONIC TOPHACEOUS GOUT IN A PREMENOPAUSAL PATIENT WITH FAMILIAL NEPHROPATHY}

${ }^{1} \mathrm{R}$ Guzel, ${ }^{1} \mathrm{~T}$ Sarpel, 'E Kozanoglu, ${ }^{2} \mathrm{~S}$ Paydas. 'Physical Medicine and Rehabilitation; ${ }^{2}$ Nephrology, Cukurova University Medical Faculty, Adana, Turkey

\subsection{6/annrheumdis-2001.477}

Background Only 5\% of gouty patients are women and $90 \%$ of them are postmenopausal at the time of onset.

Objectives To describe a delayed diagnosis in a young female patient with gouty arthritis and familial nephropathy, to mention about approach to allopurinol cutaneous hypersensitivity.

Methods A 35-year-old woman presented with a 8 year history of arthritis that became crippling in the last year. Initially she was misdiagnosed as acute rheumatic fever, and later she was treated as rheumatoid arthritis. She denied any usage of diuretics or alcohol. Pedigree evaluation revealed five cases of chronic renal failure in the family, some with gouty complaints. On presentation; blood pressure was $120 / 70 \mathrm{mmHg}$, she was Steinbrocker functional class IV. She had large, tophi over metatarsophalangeal joints and tenderness with motion of ankles, wrists and right elbow. Monosodium urate crystals were demonstrated in synovial fluid. Serum urate level was $14 \mathrm{mg} / \mathrm{dl}$, uric 
acid excretion and creatinine clearance was low, being $290 \mathrm{mg} /$ day and $37 \mathrm{~mL} / \mathrm{min}$ respectively. Additional abnormal investigations included a haematocrit of $27.3 \%$, urea of $30 \mathrm{mg} / \mathrm{dl}$, ESR of $78 \mathrm{~mm} / \mathrm{h}$. Serum trigliceride and total lipid were elevated being $291 \mathrm{mg} / \mathrm{dl}$ and $1281 \mathrm{mg} / \mathrm{dl}$ respectively. On USG bilateral soft tissue swelling in the axillar region were found to be compatible with lipomatosis. Urolithiasis was not observed. With these findings and family history she was suspected to have hereditary familial hyperuricemic nephropathy.

After resolution of the acute attack with indomethacin, allopurinol treatment was started but had to be discontinued upon occurrence of widespread erythematous rash. She was hospitalised and desensitisation regime lasting 10 days was commenced. After desensitisation, she was free of symptoms with $300 \mathrm{mg} /$ day allopurinol and $0.5 \mathrm{mg} /$ day colchicine. Four months later, she developed oral ulcers. Since there was a doubtful genital ulcer history she was examined for Behçet's disease. Pathergy test was negative and unexpectedly she was HLA B27 positive but no other signs suggesting spondyloartropathy was present. Oral ulcers disappeared after allopurinol dosage has been lowered to $150 \mathrm{mg} /$ day, the rash or ulcers has not recurred. The tophii were dissolved, renal functions and blood pressure have not deteriorated over time, there has been dramatic improvement of her symptoms with normalisation of serum urate levels, she is now Steinbrocker class II.

Results

Conclusion Hyperuricemia or gout appearing at an early age in a female is usually associated with progressive renal failure. Early recognition of this disorder is important since allopurinol therapy may ameliorate the progression of the renal lesion. In cases of hypersensitivity to allopurinol oral desensitisation is a feasible approach.

\section{AB0156 THE EFFICACY OF ALENDRONATE IN POSTMENOPAUSICAL OSTEOPOROSIS}

1J Fernández-Melón, ${ }^{1} \mathrm{M}$ Bernad, ${ }^{1} \mathrm{~A}$ García-Aparicio, ${ }^{1} \mathrm{G}$ Bonilla, ${ }^{2} \mathrm{ML}$ Gonzalez, ${ }^{3}$ ME Martinez, ${ }^{1}$ E Martín-Mola. ${ }^{1}$ Rheumatology; ${ }^{2}$ Biochemistry Service, Hospital Gomez Ulla, Madrid, Spain; ${ }^{3}$ Biochemistry Service, Hospital La Paz

\subsection{6/annrheumdis-2001.478}

Background This is a prospective study of bone mineral density in postmenopausical women treated with alendronate.

Objectives To evaluate the efficacy of alendronate in postmenopausical osteoporotic women for 1, 2 and 3 years.

Methods In a prospective study, we included 98 women diagnosed of postmenopausical osteoporosis attended from 1997 to 2000. The mean age was 59.07 (SD: 6.68). Patients received alendronate $10 \mathrm{mg}$ daily, they were allowed to take calcium and vitamine $\mathrm{D}$ supplementation. The subjects were assessed at baseline, 12, 24 and 36 months for bone mineral density (BMD) measurements and X-ray and every 6 months blood and urinary biochemistries and markers of bone turnover were done.

Results Sixteen patients (16\%) have dropped out because of adverse effects, the most common was gastrointestinal events. 34 $(34.6 \%)$ patients had previous fractures (17 had spine fractures, 12 Colles's fractures and one hip fracture). Three patients on treatment with alendronate had new fractures (1 spine, 1 scaphoid and one Colles's fracture). 70, 24 and 7 subjects have completed one, two and three years of treatment, respectively. The results were analysed by Student's t-test. Patients treated with alendronate for 1 year had significantly greater improvement in BMD at spine. The mean BMD at baseline was 0.373 vs $0.773(\mathrm{p}<0.005)$ and at hip 0.665 vs 0.643 at baseline $(\mathrm{p}<$ 0.005). Patients who completed two years had similar values of $\mathrm{BMD}$ as the year before, the mean BMD was 0.745 at spine and 0.646 at hip.

Conclusion Patients treated with alendronate for one year had significantly greater improvement in BMD at both the spine and hip.

\section{AB0157 PARANEOPLASIC HYPERCALCEMIA COMPLICATING A B CELL NON-HODGKIN LYMPHOMA (NHL)}

E Karoubi Nordon, E Palazzo, SA Rouidi, O Meyer. Rhumatology, BICHAT, Paris, France

\subsection{6/annrheumdis-2001.479}

Background Hypercalcemia is an unfrequent manifestation of $\mathrm{B}$ cell NHL. We describe a case report of hypercalcemia secondary to PTH-rp production, inaugurating a B-cell NHL.

Objectives A 77 year old woman was admitted with dorsalgia. Physical examination was negative except neuropsychological hyperexcitability.

Biological data rrevealed an increased calcemia $(4.2 \mathrm{mmol} / \mathrm{l})$ with decreased phosphoremia $(0.45 \mathrm{mmol} / \mathrm{l})$ suggesting a hyperparathyroidism. However, PTH(RIA) was low $(3.5 \mathrm{pg} / \mathrm{ml}, \mathrm{N}=$ 11.0-62.0) and $1.25(\mathrm{oh}) 2 \mathrm{~d} 3$ level was in the normal range $(40$ $\mathrm{yg} / \mathrm{l}, \mathrm{N}=15-80)$. PTH-rp was moderatly increased (2.1 ymol/l, $\mathrm{N}<1.5$ ). Bone marrow aspiration was normal. No sign for osteolysis was present on bone X-ray, CT scan and MRI. The abdominal CT scan and abdominal MRI revealed a retroperitoneal mass. A needle biopsy was diagnostic for NHL B type. LDH were elevated to $3290 \mathrm{U} / \mathrm{l}(\mathrm{n}<470)$. Other lymphoid tissue involvment was limited to the spleen. IV farmidronate was successfuly adminitred for treatment of hypercalcemia.

Methods

Results Malignat hypercalcemia occurs in 14p.cent of leukaemia and lymphoma. Among NHL, T cell lymphoma positive for HTLV-1, are more frequently associated with hypercalcemia mediated by production of $1-25(\mathrm{OH}) 2 \mathrm{D} 3$ or lymphotoxin/OAF. Less than 3 p.cent of B cell NHL are associated with a paraneoplasic hypercalcemia. Two hypercalcemic mediators have been caracterised: PTH-rp and/or OAF

Conclusion Humoral hypercalcemia mediated by PTH-rp is a rare complication of $\mathrm{B}$ cell-NHL. Hypophosphatemia with a decreased PTH plasma level must alert for this mechanism.

\section{REFERENCES}

1 Orcel P. Hypercalcémie des affections malignes, ed. Masson, 1996

2 Daroszewska A, Bucknall RC, Chu P, Fraser WD. Severe hypercalcemia in B-cell Lymphoma: combined effects of PTH-rp, IL-6 and TNF. Postgrad Med J. 1999

3 Hanihara T, Takahashi T. PTH-rp associated Hypercalcemia in probable intravascular lymphoma of B-cell type. Am J Hematol. 1996

\section{OP0011 CONSTRUCTION OF A PHYSICAL MAP AND IDENTIFICATION OF CANDIDATE GENES FOR FAMILIAL CHONDROCALCINOSIS AT CHROMOSOME 5P15}

${ }^{1} \mathrm{~A}$ Pendleton, ${ }^{1} \mathrm{GD}$ Wright, ${ }^{2} \mathrm{MD}$ Doherty, ${ }^{3} \mathrm{R}$ Shiang, ${ }^{3} \mathrm{~A}$ Hughes. ${ }^{1}$ Rheumatology, Musgrave Park Hospital, Belfast, UK; ${ }^{2}$ Academic Rheumatology, University of Nottingham, Nottingham, UK; ${ }^{3}$ Medical Genetics, Queens University Belfast, Belfast, UK

10.1136/annrheumdis-2001.480

Background A gene for familial chondrocalcinosis was previously mapped to a locus (CCAL2) on chromosome 5p. ${ }^{1}$ The purpose of the study was to identify this gene and investigate its role in 